\title{
Surgical Treatment of Scarring Alopecia Associated with Acne Keloidalis Nuchae
}

\author{
Keiichi Tamagawa, Daichi Morioka* (ㄷ, Rikako Suminaga, Zhuo Zhang, Ayako Aoki, \\ Yuka Shibuya, Hiroki Utsunomiya
}

Department of Plastic Surgery, Showa University, Tokyo, Japan

Email:*dmorioka@gmail.com

How to cite this paper: Tamagawa, K., Morioka, D., Suminaga, R., Zhang, Z., Aoki, A., Shibuya, Y. and Utsunomiya, H. (2019) Surgical Treatment of Scarring Alopecia Associated with Acne Keloidalis $\mathrm{Nu}-$ chae. Modern Plastic Surgery, 9, 14-17. https://doi.org/10.4236/mps.2019.91003

Received: November 29, 2018

Accepted: December 26, 2018

Published: December 29, 2018

Copyright $\odot 2019$ by authors and Scientific Research Publishing Inc. This work is licensed under the Creative Commons Attribution International License (CC BY 4.0). http://creativecommons.org/licenses/by/4.0/

\section{Open Access}

\begin{abstract}
Acne keloidalis nuchae $(\mathrm{AKN})$ is a relatively rare chronic inflammatory condition that leads to alopecia on the occipital scalp. Multiple large keloids and alopecia associated with long-lasting folliculitis impair the psychosocial functioning of patients. We report successful treatment of alopecia associated with AKN. When a 23-year-old male was referred to us, a large area of alopecia and multiple keloids associated with $\mathrm{AKN}$ were found. Following total excision of the lesion, the defect was reconstructed with two rotation flaps elevated bilaterally. Most patients with AKN undergo conservative treatments including oral antibiotics and local steroid injections. As surgical treatments, excision followed by skin grafting or second-intention healing has been reported. However, all of the previously-reported treatments have left alopecia on the occipital region. Although long scars might be left in the scalp, local flap reconstruction would be an option for the treatment of large areas of alopecia associated with AKN.
\end{abstract}

\section{Keywords}

Acne Keloidalis Nuchae, Alopecia, Rotation Flap

\section{Introduction}

Acne keloidalis nuchae $(\mathrm{AKN})$ is an idiopathic chronic inflammatory condition characterized by the formation of papules and pustules that ultimately develop into keloid-like masses on the occiput and nape of the neck [1] [2]. This hyperproliferative disorder typically occurs in young adult males of African origin [2] [3], but it is relatively rare in the Asian population [4].

The relapsing condition leads to sparse hair or multiple large keloids on the occipital scalp [1] [3]. Scarring alopecia that has resulted from long-lasting folli- 
culitis cannot be cured by conservative treatment, and impairs the psychosocial functioning and self-esteem of patients [3]. Although many authors have reported the effectiveness of nonsurgical and surgical treatments, such treatments attempt to prevent the recurrence of this inflammatory condition; very few reports have focused on the treatment of the alopecia associated with AKN [1]. Here, we present a case of a Japanese male patient with scarring alopecia associated with AKN that was successfully treated with local flap reconstruction following total excision of the lesion.

\section{Case Report}

The patient was a 23-year-old male with no medical history (Table 1). He had suffered from severe folliculitis and acne on the occipital area since the age of 17 years. Since the diagnosis of AKN had been made by dermatologists from a biopsy, the lesion had been treated with oral antibiotics and antibiotic ointment, and occasionally with incision and drainage.

When the patient was referred to us, an extensive scarring alopecia and multiple keloids associated with AKN were found (Figure 1(a)). We proposed several treatment options including serial excision, tissue expansion, and skin grafting. The patient decided to undergo one-stage reconstruction using a local flap.

The skin defect after total excision with subcutaneous fat tissue was $6 \times 14 \mathrm{~cm}$ in size (Figure 2(a)). Two rotation flaps, each $12 \times 11 \mathrm{~cm}$ in size, were bilaterally elevated, including the galea in the upper part (Figure $2(\mathrm{~b})$ ). The defect was closed with no tension (Figure 2(c)).

Histological findings revealed a dense follicular inflammatory infiltrate consisting of neutrophils and lymphocytes. Thick dermal fibrosis, perifollicular abscess formation, and disrupted hair follicles were also seen.

The early postoperative course was uneventful. Although keloids and minor infections were present on the edge of the scar after surgery three months after surgery, these conditions were effectively treated with local steroid injections and oral antibiotics. A 1-year follow-up examination revealed excellent aesthetic results with no evidence of recurrence (Figure 1(b)).

\section{Discussion}

Most patients with mild to moderate AKN undergo conservative treatments including oral antibiotics for acne and local steroid injections for keloids. Several authors have reported that laser hair removal is an option to prevent relapsing folliculitis [5].

For patients refractory to those approaches, surgical treatments are performed. As hair follicles typically penetrate the subcutaneous fat, excision should extend to the deep subcutaneous tissue or fascia [6]. Primary closure of the skin defect is an ideal option for horizontally narrow lesions [6]. Closure options after the excision of comparatively extensive lesions include split-thickness skin 
Table 1. Patient characteristics.

\begin{tabular}{ll}
\hline Ethnicity & Japanese \\
Age and sex & 23 years old, male \\
Weight & $68 \mathrm{~kg}$ \\
Height & $161 \mathrm{~cm}$ \\
Smoking status & nonsmoker \\
Occupation & Office worker \\
Past medical history & None \\
Family history & None \\
\hline
\end{tabular}

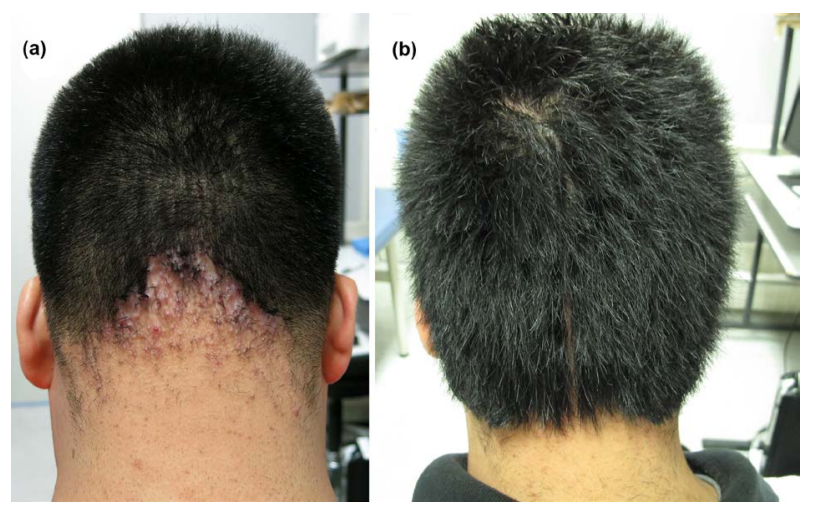

Figure 1. Photograph of the lesion at the first presentation (a). Extensive AKN-associated alopecia is seen. One-year postoperative view with an excellent aesthetic result (b).
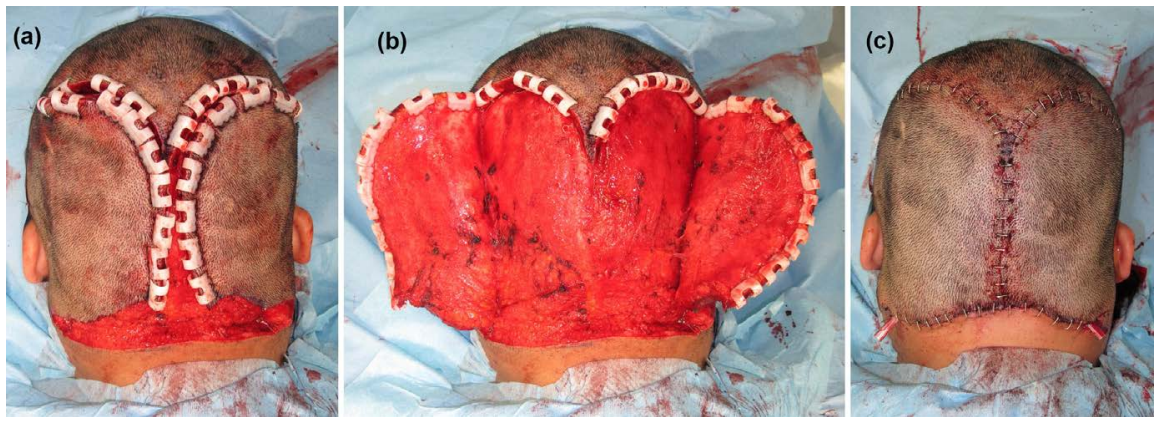

Figure 2. Intraoperative photographs. After the total excision (a), two rotation flaps were bilaterally elevated (b). The defect was successfully closed (c).

grafting, second-intention healing, and electrosurgery [6] [7]. However, whether medical or surgical, most of the previously reported treatments have left scarring alopecia on the occipital region, which leads to psychosocial impairment, especially in males with short hair [3].

Gloster [6] reported the staged excision of an extensive lesion. Pestalardo et al. [8] reported total excision using a tissue expander. Both authors demonstrated excellent outcomes for the treatment of $\mathrm{AKN}$-associated alopecia, but both maneuvers required multistage surgery [1] [6] [8]. Although long scars might re- 
main in the scalp, the present one-stage reconstruction using a local flap following total excision of the lesion would be an option for the treatment of extensive alopecia associated with AKN.

\section{Funding}

The authors received no financial support for the research, authorship, and/or publication of this article.

\section{Ethical Approval}

For this kind of article formal, consent is not required.

\section{Informed Consent}

Patient provided written consent before his inclusion in this report.

\section{Patient Consent}

Patient provided written consent for the use of images.

\section{Conflicts of Interest}

The authors declared no potential conflicts of interest with respect to the research, authorship, and/or publication of this article.

\section{References}

[1] Maranda, E.L., Simmons, B.J., Nguyen, A.H., et al. (2016) Treatment of Acne Keloidalis Nuchae: A Systematicreview of the Literature. Dermatologic Therapy (Heidelb), 6, 363-378. https://doi.org/10.1007/s13555-016-0134-5

[2] East-Innis, A.D.C., Stylianou, K., Paolino, A., et al. (2017) Acne Keloidalis Nuchae: Risk Factors and Associated Disorders-A Retrospective Study. International Journal of Dermatology, 56, 828-832. https://doi.org/10.1111/ijd.13678

[3] Ogunbiyi, A. (2016) Acne Keloidalis Nuchae: Prevalence, Impact, and Management Challenges. Clinical, Cosmetic and Investigational Dermatology, 9, 483-489. https://doi.org/10.2147/CCID.S99225

[4] Na, K., Oh, S.H. and Kim, S.K. (2017) Acne Keloidalis Nuchae in Asian: A Singleinstitutional Experience. PLoS One, 12, e0189790.

https://doi.org/10.1371/journal.pone.0189790

[5] Tawfik, A., Osman, M.A. and Rashwan, I. (2018) A Novel Treatment of Acne Keloidalis Nuchae by Long-Pulsed Alexandrite Laser. Dermatologic Surgery, 44, 413-420.

[6] Gloster, H.M.J. (2000) The Surgical Management of Extensive Cases of Acne Keloidalis Nuchae. Archives of Dermatology, 136, 1376-1379.

https://doi.org/10.1001/archderm.136.11.1376

[7] Glenn, M.J., Bennett, R.G. and Kelly, A.P. (1995) Acne Keloidalis Nuchae: Treatment with Excision and Second-Intention Healing. Journal of the American Academy of Dermatology, 33, 243-246. https://doi.org/10.1016/0190-9622(95)90242-2

[8] Pestalardo, C.M., Cordero, A.J., Ansorena, J.M., et al. (1995) Acne Keloidalis Nuchae. Tissue Expansion Treatment. Dermatologic Surgery, 21, 723-724.

https://doi.org/10.1111/j.1524-4725.1995.tb00278.x 